\title{
Influence of a Program Combining Amusement and Exercise on Subjective Well-Being: Six-Month Intervention Study with a Complex-Type Program for Community-Dwelling Elderly Subjects
}

\author{
Nami Kawabata1,2, Tadayuki Iida ${ }^{3 *}$, Hideki Miyaguchi ${ }^{4}$, Masafumi Kunishige ${ }^{5}$, Chinami Ishizuki ${ }^{4}$, \\ Hiroko Hashimoto ${ }^{6}$, Yasuhiro Ito ${ }^{7}$, Toshihide Harada ${ }^{3}$ \\ ${ }^{1}$ Program in Biological System Sciences, Graduate School of Comprehensive Scientific Research, Prefectural University of \\ Hiroshima, Shobara, Japan \\ ${ }^{2}$ Department of Rehabilitation/Occupational Therapist, Faculty of Health Sciences, Hiroshima Cosmopolitan University, \\ Hiroshima, Japan \\ ${ }^{3}$ Department of Physical Therapy, Faculty of Health and Welfare, Prefectural University of Hiroshima, Mihara, Japan \\ ${ }^{4}$ Department of Human Behavior Science of Occupational Therapy, Health Sciences Major, Graduate School of Biomedical \& \\ Health Sciences, Hiroshima University, Hiroshima, Japan \\ ${ }^{5}$ Division of Occupational Therapy, Graduate School of Biomedical \& Health Sciences, Hiroshima University, Hiroshima, Japan \\ ${ }^{6}$ Department of Occupational Therapy, Faculty of Health Sciences, Morinomiya University of Medical Sciences, Osaka, Japan \\ ${ }^{7}$ School of Health Sciences, Fujita Health University, Toyoake, Japan \\ Email: ^iida@pu-hiroshima.ac.jp
}

How to cite this paper: Kawabata, N., Iida, T., Miyaguchi, H., Kunishige, M., Ishizuki, C., Hashimoto, H., Ito, Y. and Harada, T. (2018) Influence of a Program Combining Amusement and Exercise on Subjective Well-Being: Six-Month Intervention Study with a Complex-Type Program for Community-Dwelling Elderly Subjects. Open Journal of Preventive Medicine, 8, 266-281. https://doi.org/10.4236/ojpm.2018.88023

Received: July 20, 2018

Accepted: August 28, 2018

Published: August 31, 2018

Copyright ( 2018 by authors and Scientific Research Publishing Inc. This work is licensed under the Creative Commons Attribution International

\begin{abstract}
Background: Health promotion for the elderly mainly targets improvements in physical function, and a lack of strengthening of subjective well-being as well as the creation of interaction-providing opportunities for activity and participation has been reported. Evaluations of positive and negative aspects for subjective well-being are needed. Elderly subjects were intervened through a 6-month complex-type program combining amusement and exercise and its influences on subjective well-being and physical and physiological functions were investigated. Methods: Subjects in this survey were 37 healthy elderly females living in M city, Hiroshima Prefecture (age: $69.7 \pm 5.9$ years old), and the survey was performed between September 2016 and March 2017. The complex-type program comprised amusement and exercise programs. The survey was performed at 4 time points during the intervention period: before the intervention and 1,3, and 6 months during the intervention. Subjective well-being (Japanese version of the Subjective Well-being Inventory (SUBI): Mental health scores, Mental fatigue scores), salivary amylase
\end{abstract}


License (CC BY 4.0).

http://creativecommons.org/licenses/by/4.0/

Open Access levels, and the locomotive syndrome risk test (two-step test, stand-up test, and 25-question risk assessment) were surveyed at each time point. Regarding the duration of the intervention as a factor, changes in salivary amylase levels were analyzed using repeated measures one-way ANOVA and SUBI was tested using the Friedman test (EZR Ver 1.32). In addition, the relationship between the locomotive syndrome risk level and duration of the intervention was examined using Fisher's test. Results: SUBI and the locomotive syndrome risk level significantly differed with time during the intervention. Slight changes were observed in salivary amylase levels during the intervention. Conclusion: The present results suggest that the complex-type program promoted interactions among community-dwelling elderly subjects and positively influenced the maintenance of and improvements in physical and physiological functions. These changes may be associated with favorable influences on the positive and negative aspects of subjective well-being.

\section{Keywords}

Subjective Well-Being, SUBI, The Elderly, Amusement, Exercise

\section{Introduction}

Japan has one of the longest average life spans and healthy life expectancies in the world. The difference between the average life span and healthy life expectancy did not decrease for approximately 12 years between 2001 and 2013 [1]. The Ministry of Health, Labor, and Welfare stated that the maintenance of functions to preserve a social life is important for promoting health and extending the healthy life expectancy of the elderly, and also that the strengthening of measures that focus on the psychological and social aspects of health, such as subjective health, subjective well-being, and life satisfaction, in addition to physical aspects is needed for the elderly [2]. The involvement of periodic exercise and physical activity in the physical function [3] [4] [5] and subjective health [6] [7] of the elderly and their contribution to social aspects [8] [9] have already been reported. However, McAuley \& Rudolph reviewed 38 studies and reported no consistent effects of exercise on mental health [10]. They found that many studies focused on negative psychological aspects, such as depression and anxiety, rather than positive psychological aspects, including well-being and life satisfaction, and suggested that participation in exercise and physical activity is associated with improvements in subjective well-being, whereas physical strength is not. Larson showed that subjective well-being is the most strongly related to subjective health, and also that subjective well-being and life satisfaction are closely associated with the health of the elderly [11]. McAuley et al. investigated the roles of participation in physical activity and social support in the subjective well-being of the elderly, and the findings obtained suggested that the social relationship essential for an exercise environment is an important determinant of the subjective well-being of the elderly [12]. Therefore, previous health promo- 
tion programs for the elderly may have being lacking from the viewpoint of strengthening subjective well-being and the creation of interactions as an opportunity for activity and participation. Moreover, the measurement of subjective well-being consisted of a feeling of satisfaction and both positive and negative emotions [11] [13], suggesting that evaluations of positive and negative aspects are necessary.

The use of amusement devices has been attracting attention because an interaction is created and a "pleasant stimulation" evokes positive emotions, which improve motivation and activeness and promote positivity. The influence of these devices on improvements in motor function and the activation of communication have been reported [14] [15] [16] [17] [18]. However, participants subjectively evaluated whether "it was a pleasant stimulation" in many of these studies, whereas an objective evaluation using physiological function has not yet been performed. We previously reported that active responses were promoted by interactions through amusement at a day care service center using salivary amylase levels as a physiological index [19]. Based on these findings, we considered it possible to prepare a health promotion program for the elderly that is effective for psychological aspects by combining interactions and exercise through amusement.

In the present study, the influence of continuous participation in a complex-type program combining interactions and exercise through amusement on subjective well-being was investigated from the positive and negative aspects of subjective well-being in community-dwelling elderly subjects using the "Japanese version of the Subjective Well-being Inventory (SUBI)" [20] [21]. Furthermore, the influence of the complex-type program on physiological function was investigated using salivary amylase levels, while its effects on physical function were examined using the locomotive syndrome risk test.

\section{Materials and Methods}

\subsection{Subjects}

Subjects were healthy elderly females living in M city, Hiroshima Prefecture, who voluntarily applied to the public recruitment notice for participation in the present study. Forty-seven subjects gave consent after an explanation of the study content and method and forty-six did not conflict with the exclusion criteria described below. Thirty-seven subjects (69.7 \pm 5.9 years old) continuously participated in the complex-type program twice weekly and physical strength measurements and saliva collection were conducted. These subjects were included in the analysis. The sample size was found from the changes in salivary amylase levels to a minimum of twenty-six people (limit of error: $120 \mathrm{kIU} / \mathrm{L}$, standard deviation: $300 \mathrm{kIU} / \mathrm{L}$, confidence interval: 95\%). Therefore, thirty-seven subjects in this study were sufficient for data analysis.

Exclusion criteria

1) Mental diseases, such as depression.

2) A diagnosis of dementia. 
3) Cognitive function test (Mini-Mental State Examination: MMSE) $\leq 23$.

4) Difficulty in verbal communication, unable to respond verbally to questions.

5) Previous medical history of diseases that limit exercise (heart disease and cerebral dysfunction) and acute changes in or the deterioration of health potentially caused by participation in this study.

6) Measurements accompanying this study are difficult.

This study was performed in conformity to the Declaration of Helsinki after approval by the Research Ethics Committee of the Prefectural University of Hiroshima (approval number: $16 \mathrm{MH} 012$ ).

\subsection{Complex-Type Program}

A facility for the amusement/exercise complex program (facility) was prepared in $\mathrm{M}$ city, Hiroshima Prefecture. The complex-type program comprised amusement and exercise programs. In the amusement program, blackjack and darts were prepared and always performed. In the exercise program, 6 exercise devices were prepared and an exercise menu was individually prepared for subjects.

1) Flow of the complex-type program

The complex-type program was performed for approximately 90 minutes per session (13:00 - 14:30 and 15:00 - 16:30) twice weekly in the afternoon of week days and excluded Saturday, Sunday, and public holidays. Subjects selected days and times based on their convenience and a maximum of 16 subjects were included in each group. The flow of the program was as follows: After an approximately 30-minute warm-up program, subjects were divided into groups starting with the amusement or exercise program. Randomized according to the subjects of participants in each sessions (13:00 - 14:30 and 15:00 - 16:30), divided into group A and group B. In consideration of safety, the subjects in each group was 5 to 8 people. The group A starting with the amusement program performed the 30-minute exercise program after the 30-minute amusement program. The group B starting with the exercise program performed the 30-minute amusement program after the 30 -minute exercise program (Figure 1 ).

2) Amusement program

Employees of cooperative research institutions trained for recreation and nursing were engaged in the amusement program as staff.

a) Blackjack

A staff member served as a dealer and subjects were players. The basic rules were as follows: Players add the points of cards on hand for a total score not exceeding 21; the player wins if the total score exceeds that of the dealer. The players had chips for 50 points at the beginning and they played a game with the dealer to increase chips on hand. Chips were bet, but not exchanged for money and the game winner received only praise from group members and staff.

b) Darts

Each subject threw 3 darts one time and the second throw was performed after 


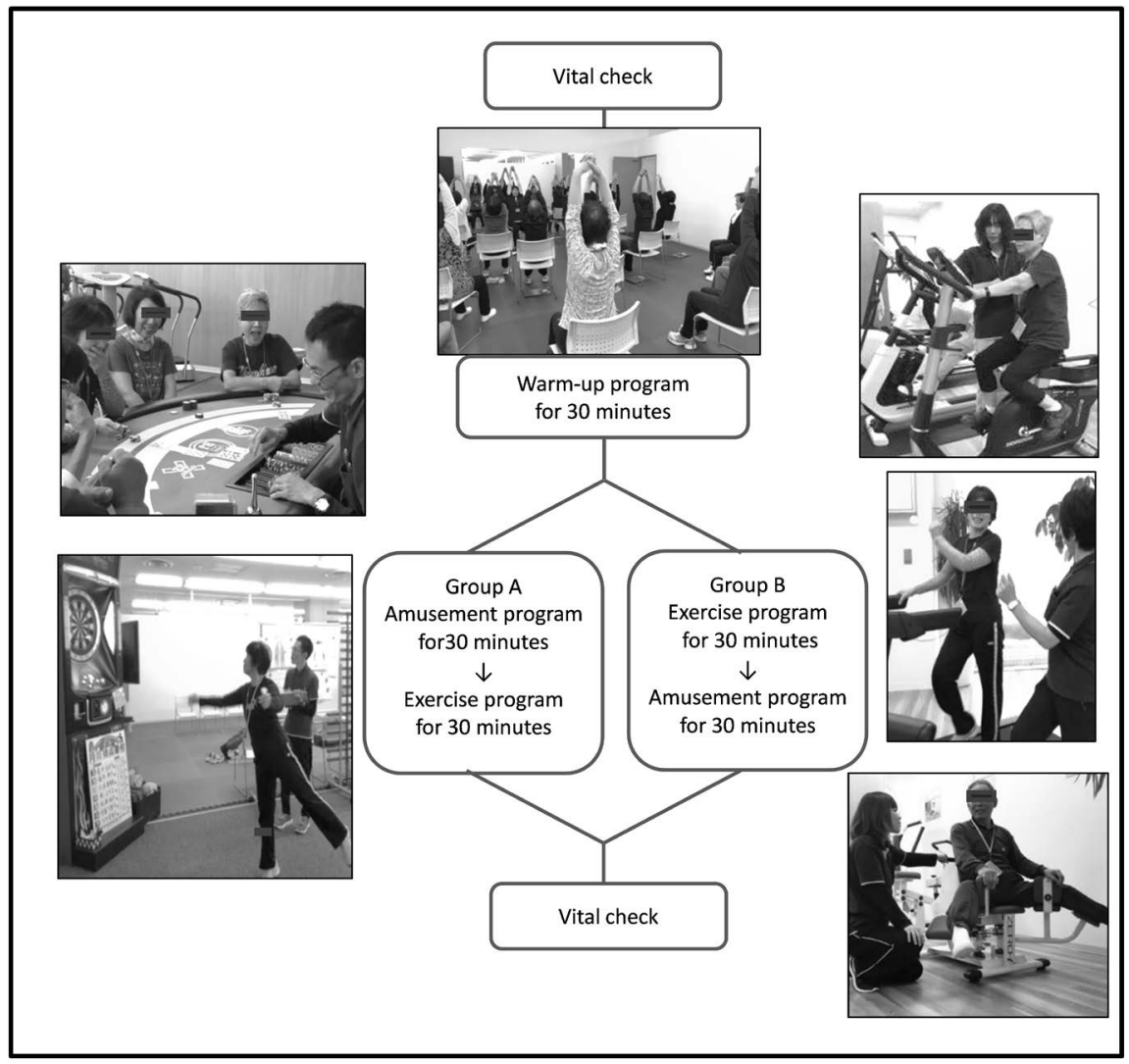

Figure 1. Flow chart of the complex-type program.

all group members completed throwing. They competed for the total score of the 6 darts thrown in 2 trials. The score was added for the double band (outer ring) and triple band (inner ring) on the dart board at the odds of the normal rule. Since many subjects had never played darts before, instructions on how to throw darts were provided at the beginning of its introduction.

3) Exercise program

Vital checks and the confirmation of the physical condition of subjects were performed by nurses before and after the program to adjust the exercise menu. The exercise program was performed under supervision by one occupational therapist and 3 health fitness programmers. The exercise menu, such as the combination of machines, was prepared to correspond to an individual's condition by the occupational therapist and health fitness programmer. Approximately 10 minutes of aerobic exercise using a treadmill (ADVENTURE 1, Johnson Health Tech Japan Co., Ltd.), upright bike (Comfort 7, Johnson Health Tech Japan Co., Ltd.), recumbent bike (COMFORT R, Johnson Health Tech Japan Co., Ltd.), or cross trainer (ANDES 3, Johnson Health Tech Japan Co., Ltd.), approximately 10 minutes on a whole-body vibration machine (Crazy Fitness, RONNE JAPAN, Inc.), resistance exercise using an abdominal muscle exercise machine (wondercore 2, OAK LAWN MARKETING. INC.), and stretching using 4 types of dynamic stretching machines for approximately 10 minutes in total (Shoulder Elevation (smart Type), Chest Extension (smart Type), Adductor 
Extension (smart Type), and Hip Flex (smart Type); ZERO (Initialize Inc.) were performed.

\subsection{Survey Items}

The survey was performed at 4 time points during the intervention period between September 2016 and March 2017: Before the intervention in September 2016 and 1, 3, and 6 months after the initiation of the intervention in October 2016, December 2017, and March 2017, respectively. A survey measurement day was set on a day other than the days with the complex program at each time point using a questionnaire and motor function evaluation. In addition, saliva was collected before and after the complex-type program at each time point and salivary amylase levels were measured.

1) Questionnaire

The "Japanese version of the Subjective Well-being Inventory (SUBI)" [20] [21] translated from the "The Subjective Well-being Inventory (SUBI)" [22] developed by the World Health Organization (WHO) to measure subjective well-being was used. In the measurement of subjective well-being, life satisfaction is used as an index of the cognitive aspect and positive and negative emotions are investigated as emotional indices [11] [13]. SUBI was employed to measure subjective well-being from psychological, physical, and social aspects [20] [21] [22]. The scale was comprised of 2 axes: "Positive affect" and "Negative affect", and positive and negative emotions were evaluated as "Mental health scores" and "Mental fatigue scores", respectively. There were 40 questions and replies were provided through the following 3-grade evaluation: "I strongly think so", "I think so to some extent", and "I do not think so very much".

2) Measurement of changes in salivary amylase levels

Saliva was collected before the warm-up program and after the amusement and exercise programs. Saliva samples were collected by holding a Salimetrics Oral Swab (Salimetrics LLC) in the mouth for 3 minutes (maximum of $5 \mathrm{mi}$ nutes). After sampling, the swab was centrifuged at $3500 \mathrm{rpm}$ for 15 minutes and saliva was recovered and frozen. The BG5 PNP method (meeting JCCLS) was used. Since individual variations in amylase levels were previously reported to be large [23], changes in salivary amylase levels from before the introduction of the complex-type program were calculated at each time point.

3) Evaluation of physical function

In the evaluation of physical function, the locomotive syndrome risk test proposed by the Japanese Orthopaedic Association in 2007 was used to survey motor impairment and locomotor dysfunction [24]. The locomotive syndrome risk test is comprised of a two-step test [25], stand-up test [25], and 25-question risk assessment [25] [26].

The locomotive syndrome risk level was judged based on the results of these 3 tests [25]. There were 2 risk levels, as shown below:

- Risk level 1: Decreases in muscular strength and balance function already 
present, which reduced locomotive function.

Two-step test score $<1.3$.

Difficulty with one-leg standing from a $40-\mathrm{cm}$-high seat in the stand-up test (either leg).

A 25-question risk assessment score $\geq 7$.

- Risk level 2: The reduction in locomotive function has progressed.

Two-step test score $<1.1$.

Difficulty with standing from a 20 -cm-high seat using both legs in the stand-up test.

A 25-question risk assessment score $\geq 16$.

\subsection{Data Analysis}

The duration of the intervention (before the intervention and 1, 3, and 6 months after the initiation of the intervention) was regarded as a factor, and mental health scores, mental fatigue scores, changes in salivary amylase levels, two-step test scores, and 25-question risk assessment scores were regarded as dependent variables. Regarding the confirmation of the normality of changes in salivary amylase levels and two-step test scores, the Kolmogorov-Smirnov test, a histogram, and QQ plot were used. Since the normality of changes in salivary amylase levels and two-step test scores was confirmed, the mean and standard deviation were calculated and subjected to a repeated measures one-way ANOVA. When sphericity was negative in Mauchly's test of sphericity, the p-value was adjusted using the Greenhouse-Geisser method (GG-adjusted value). Regarding mental health scores, mental fatigue scores, and 25-question risk assessment scores, the median and first and third quartiles were obtained and analyzed using the Friedman test. The Bonferroni method was used for multiple comparisons. Statistical analyses were performed using EZR Ver. 1.32 [27] and the significance level was set at $\mathrm{p}<0.05$.

In the stand-up test (stand up on one leg: either leg) and locomotive syndrome risk level, the relationship with the duration of the intervention was investigated using Fisher's test.

\section{Results}

\subsection{Subjects}

The subjects were thirty-seven elderly women $(69.7 \pm 5.9$ years old; range: 60 to 81 years old, height $152.7 \pm 4.7 \mathrm{~cm}$, body weight $52.2 \pm 6.4 \mathrm{~kg}$ ). Their physical measurements were similar to the mean values for the representative national population [28]. All subjects were ADL independent, Barthel Index (BI) score [29] was 100 points (full mark). The MMSE [30] score was $29.1 \pm 1.6$ points. Also, there was no one with 23 points or less [31]. The Japanese version of the Kessler Psychological Distress Scale (K6) [32] was $3.5 \pm 3.5$ points. There were two subjects with 10 or more points, but they were not diagnosed with mental diseases by doctors (Table 1 ). 
Table 1. Subject characteristics.

\begin{tabular}{|c|c|c|c|c|}
\hline & & $\mathrm{n}$ & Mean & SD \\
\hline Sex & Female & 37 & & \\
\hline Age (years) & & & 69.7 & (5.9) \\
\hline Weight (kg) & & & 52.2 & (6.4) \\
\hline Height $(\mathrm{cm})$ & & & 152.2 & (4.7) \\
\hline BI (point) & & & 100 & 0 \\
\hline \multirow[t]{3}{*}{ MMSE (point) } & & & 29.1 & (1.6) \\
\hline & $27-24$ & 6 & & \\
\hline & $28-30$ & 31 & & \\
\hline \multirow[t]{5}{*}{ K6 Scales (point) } & & & 3.5 & (3.5) \\
\hline & $\leq 4$ & 25 & & \\
\hline & $5-9$ & 10 & & \\
\hline & $10-12$ & 1 & & \\
\hline & 13 & 1 & & \\
\hline
\end{tabular}

SD: Standard deviation.

\subsection{Questionnaire}

Significant differences were noted in the means of SUBI mental health and mental fatigue scores among the intervention time points. Mental health scores were significantly higher 1 month $(41.0,37.0$ - 45.0), 3 months $(42.0,38.0$ - 45.0), and 6 months $(41.0,38.0$ - 47.0) after the initiation of the intervention than before the intervention (37.0, 35.0 - 43.0) (Figure 2(a)). Mental fatigue scores were significantly higher 3 months (55.0, 52.0 - 58.0) and 6 months (56.0, 53.0 - 58.0) after the initiation of the intervention than before the intervention (53.0, 48.0 56.0). They were also significantly higher at 6 months than at 1 month (54.0, 50.0 - 57.0) (Figure 2(b)).

\subsection{Changes in Salivary Amylase Levels}

The mean change in salivary amylase levels was not significantly different among the intervention time points (Figure 2(c)). Slight changes were observed in salivary amylase levels in the repeated measures ANOVA (GG-adjusted, p-value of 0.065), and these changes decreased as the duration of the intervention increased.

\subsection{Motor Function}

Significant differences were noted in the mean two-step test and 25-question risk assessment scores among the intervention time points. Two-step test scores were significantly higher 1 month $(1.42 \pm 0.14), 3$ months $(1.49 \pm 0.11)$, and 6 months $(1.52 \pm 0.13)$ after the initiation of the intervention than before the intervention $(1.33 \pm 0.15)$ (Figure $3(\mathrm{a})$ ). They were also significantly higher at 3 and 6 
months than at 1 month. Furthermore, 25-question risk assessment scores were significantly lower 3 months $(5.0,8.0$ - 9.0) and 6 months $(4.0,2.0$ - 7.0) after the initiation of the intervention than before the intervention $(5.0,3.0-16.0)$ (Figure 3(b)).

Setting the cut-off value at the locomotive syndrome risk level, the number of subjects able to stand up on the stand-up test (stand up on both legs) was investigated. All subjects exhibited the ability to stand up from a $20-\mathrm{cm}$ or lower step before the intervention (Table 2(a)). Setting the cut-off value at the locomotive syndrome risk level, stand-up test results (stand up on one leg: either leg) were evaluated as described above. An association was observed with the duration of the intervention in Fisher's test $(\mathrm{p}=0.059)$ (Table $2(\mathrm{~b})$ ), while a correlation was observed between the locomotive syndrome risk level and duration of the intervention (Table 3).

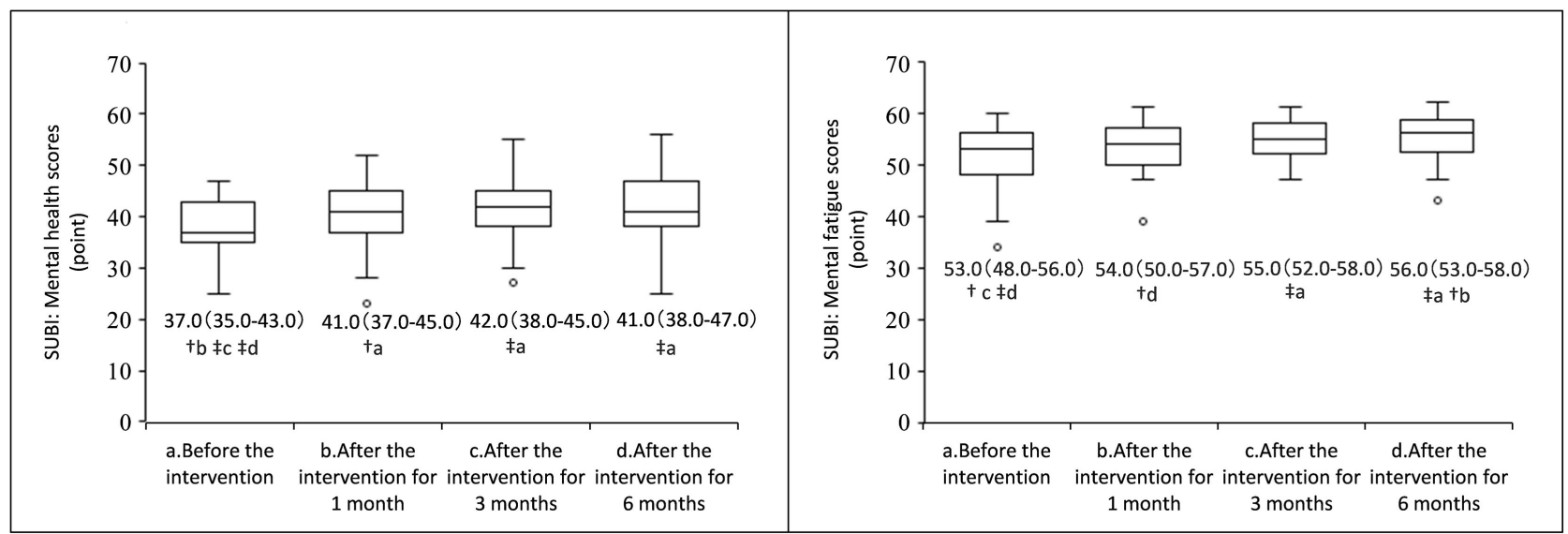

(a)

(b)

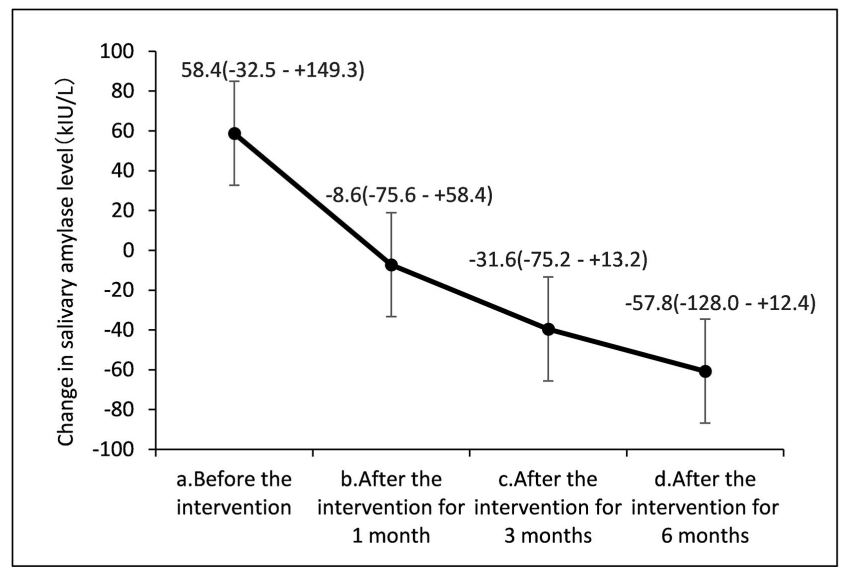

(c)

Figure 2. Relationships between SUBI, changes in salivary amylase levels, and the duration of participation in the present study. (a) SUBI (Mental health scores) on the upper left; (b) SUBI (Mental fatigue scores) on the upper right; (c) Change in salivary amylase levels on the lower left. The Friedman test: SUBI (Mental health scores) $p<0.001$, SUBI (Mental fatigue scores) $p<0.001$. Repeated measures one-way ANOVA: Change in salivary amylase levels (GG-adjusted value, $\mathrm{p}=0.065)$. Bonferroni correction: $\dagger \mathrm{p}$ $<0.05, \ddagger \mathrm{p}<0.01$. a (vs a. before the intervention); $\mathrm{b}$ (vs b. after the intervention for 1 month); $\mathrm{c}$ (vs c. after the intervention for 3 months); $d$ (vs d. after the intervention for 6 months); Figures in A and B: mean (-1SD - +1SD); Figures in C: median (first quartiles - third quartiles). 


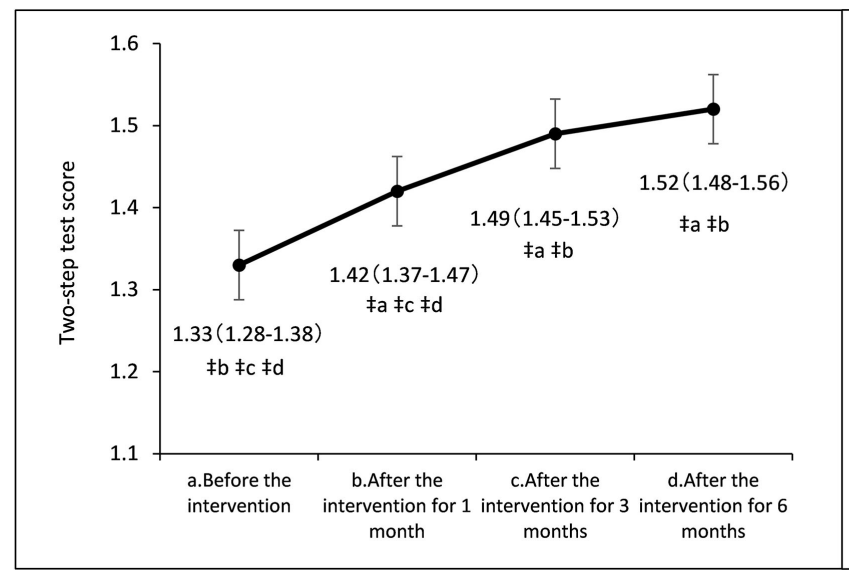

(a)

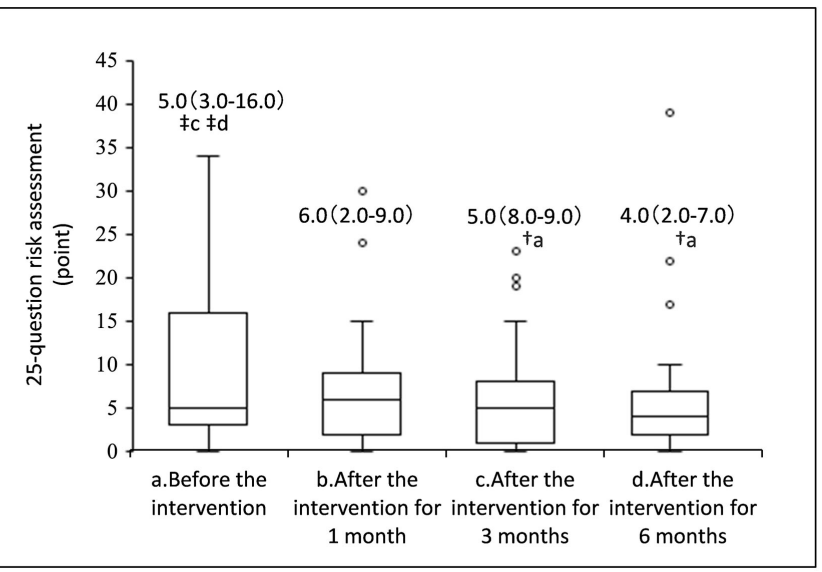

(b)

Figure 3. Relationships between two-step test and 25-question risk assessment scores and the duration of the intervention. (a) Two-step test score on the left; (b) A 25-question risk assessment on the right. Repeated measures one-way ANOVA: Two-step test score $\mathrm{p}<0.001$. Friedman test: 25 -question risk assessment $\mathrm{p}=0.004$. Bonferroni correction: $\dagger \mathrm{p}<0.05, \ddagger \mathrm{p}<0.01$. a (vs a. before the intervention); $\mathrm{b}$ (vs b. after the intervention for 1 month); c (vs c. after the intervention for 3 months); $d$ (vs d. after the intervention for 6 months). Figures in A: mean (-1SD - +1SD). Figures in B: median (first quartiles - third quartiles).

Table 2. Relationship between stand-up test results (both legs, one leg: either leg) and the duration of the intervention $(n=37)$ : The cut-off value was set at the locomotive syndrome risk level.

(a)

\begin{tabular}{lcccc}
\hline \multicolumn{4}{c}{ both legs } \\
\hline $\begin{array}{c}\text { Before the } \\
\text { intervention }\end{array}$ & $\begin{array}{c}\text { After the } \\
\text { intervention for 1 } \\
\text { month }\end{array}$ & $\begin{array}{c}\text { After the } \\
\text { intervention for 3 } \\
\text { months }\end{array}$ & $\begin{array}{c}\text { After the } \\
\text { intervention for 6 } \\
\text { months }\end{array}$ \\
\hline$\leq 20 \mathrm{~cm}$ & $37(100)$ & $37(100)$ & $37(100)$ & $37(100)$ \\
\hline
\end{tabular}

(b)

\begin{tabular}{ccccc}
\hline \multicolumn{4}{c}{ one leg: either leg* } \\
\hline $\begin{array}{c}\text { Before the } \\
\text { intervention }\end{array}$ & $\begin{array}{c}\text { After the } \\
\text { intervention for } 1 \\
\text { month }\end{array}$ & $\begin{array}{c}\text { After the } \\
\text { intervention for } 3 \\
\text { months }\end{array}$ & $\begin{array}{c}\text { After the } \\
\text { intervention for } 6 \\
\text { months }\end{array}$ \\
\hline Can not & $3(8)$ & $0(0)$ & $0(0)$ & $0(0)$ \\
$\leq 40 \mathrm{~cm}$ & $34(92)$ & $37(100)$ & $37(100)$ & $37(100)$ \\
\hline
\end{tabular}

Figures in Tables: Number of subjects (\%). *: Fisher's test: $\mathrm{p}=0.059$.

Table 3. Relationship between the number of subjects meeting the locomotive syndrome risk level and the duration of the intervention $(n=37)$.

\begin{tabular}{ccccc}
\hline & $\begin{array}{c}\text { Before the } \\
\text { intervention }\end{array}$ & $\begin{array}{c}\text { After the } \\
\text { intervention for 1 } \\
\text { month }\end{array}$ & $\begin{array}{c}\text { After the } \\
\text { intervention for 3 } \\
\text { months }\end{array}$ & $\begin{array}{c}\text { After the } \\
\text { intervention for } 6 \\
\text { months }\end{array}$ \\
\hline Not applicable & $18(49)$ & $18(49)$ & $22(59)$ & $25(68)$ \\
Risk level 1 & $7(19)$ & $16(43)$ & $12(32)$ & $9(24)$ \\
Risk level 2 & $12(32)$ & $3(8)$ & $3(8)$ & $3(8)$
\end{tabular}

Figures in Tables: Number of subjects (\%). Fisher's test: $\mathrm{p}=0.020$. 


\section{Discussion}

Community-dwelling elderly subjects were intervened through a complex-type program comprising amusement and exercise for 6 months, and the influence of continued participation in the complex-type program on subjective well-being was evaluated using SUBI. Mean mental health and mental fatigue scores representing the positive and negative aspects of subjective well-being, respectively, correlated with the duration of the intervention.

Mental health scores were significantly higher after the intervention for 1,3 , and 6 months than before the intervention, showing a favorable influence from 1 month after the initiation of the program. Physical function also correlated with the duration of the intervention, and an improvement was noted from 1 month. Previous studies demonstrated that improvements in physical function by aerobic exercise increased self-efficacy [33] [34], which may have led to a sense of accomplishment and self-confidence in carrying out the program, thereby influencing mental health scores. Mental fatigue scores were significantly higher after 3 and 6 months of the intervention than before the intervention as well as at 6 months than at 1 month, showing a positive influence from 3 months of the intervention. Yasunaga et al. examined the influence of an exercise habit on subjective well-being and clarified that the direct effect of the exercise habit was the maintenance of ADL, which preserved favorable subjective health, thereby indirectly influencing subjective well-being [35]. McAuley \& Rudolph reviewed previous studies and suggested that the duration of the program affected the findings of studies in which a favorable association was noted between exercise and mental health, indicating that mental health improved as the duration of the program increased [10]. These findings demonstrate that more time is needed for effects to appear as changes in mental fatigue scores than changes in mental health scores. Previous studies also suggested that improvements in subjective well-being are influenced by participation in physical activity, social support, and social relationships, but not by the direct effects of improvements in physical strength and physical function [10] [12] [35] [36]. Therefore, interventions through the amusement/exercise complex program not only improved physical function, social support and human relationships were created, i.e., social participation and support may have been promoted by continuously participating in the complex-type program, which may have led to improvements in physical function and human relationships, thereby improving the mental health and mental fatigue scores of subjective well-being.

The physiological index, amylase levels, was measured to investigate the comfort of subjects performing the program. An association was observed between mean changes in salivary amylase levels and the duration of the intervention ( $\mathrm{p}$ $=0.065$ ), and this relationship was weaker than that before the intervention. Yamaguchi et al. reported that an unpleasant stimulation increases salivary amylase activity levels while a pleasant stimulation causes a decrease, suggesting that pleasant and unpleasant feelings are distinguishable based on salivary amylase levels [37] [38]. Shimizu et al. showed that smiling induced psychological 
changes, such as reductions in negative emotions and improvements in mood, and psychological changes contributed to reducing salivary amylase activity [39]. We previously suggested that an active response based on amylase activity was promoted by interactions through amusement in elderly day care services and subjects felt comfortable with communicating with others through amusement [19]. In the complex-type program employed in the present study, subjects participated in individual exercise programs and blackjack as an amusement program. They may have gradually got close to each other by interactions through blackjack and formed new relationships with others, which may have been pleasant [19]. Therefore, salivary amylase levels slightly decreased, indicating that the amusement/exercise complex program was enjoyable.

The locomotive syndrome risk test (the stand-up test, two-step test, and 25-question risk assessment) was employed as a physical function index. An association was noted between the locomotive syndrome risk level and duration of the intervention, suggesting that the number of subjects with a low or no locomotive syndrome risk level increased as the duration of the intervention became longer. Kitada et al. suggested that a high physical activity level leads to a decrease in the locomotive syndrome risk [40]. McAuley et al. [12] investigated the roles of participation in physical activity and social support in the subjective well-being of the elderly and suggested that the social relationship essential for the exercise environment is an important determinant of subjective well-being in the elderly. An environment enabling periodic social participation, not an environment for simply performing aerobic exercise, was provided to subjects in order to promote interactions with others; therefore, subjects actively participated in the exercise program and their physical function may have more effectively improved. The results of the present study were similar to these findings: the exercise program may have improved lower limb muscular strength and contributed to the maintenance of and improvements in locomotive function including balance ability and subjective health. In addition, previous studies reported that locomotive function and subjective health were associated with survival [41] [42]. The amusement/exercise complex program of the present study may contribute to the maintenance of and extension of healthy life expectancy.

There were limitations in the present study. Subjects were healthy elderly individuals who voluntarily applied to the public recruitment notice for participation in the study, showing that they were highly health-conscious in daily life. Accordingly, their subjective well-being was already high to some extent before the intervention. Moreover, subjects were limited to females in a region and no control group was set. Therefore, there may be an issue with the generalization of the study results. However, a correlation was observed with the duration of the intervention despite subjective well-being being high, newly suggesting that the program had a favorable influence on subjective well-being, for which it was previously difficult to acquire an effect. Regarding future tasks, studies setting a control group and including male subjects need to be performed. 


\section{Conclusion}

The amusement/exercise complex program employed in the present study led to interactions between community-dwelling elderly subjects, the maintenance of and improvements in physical function, the centering of lower limb function, and a favorable influence on physiological function. These effects may subsequently have had a favorable influence on positive and negative aspects of subjective well-being.

\section{Acknowledgements}

We are grateful to the participants of this study. We also thank the staff of the Prova Group for their support and cooperation in the opening and operating of the facility.

\section{Conflicts of Interest}

The authors declare no conflicts of interest regarding the publication of this paper.

\section{References}

[1] Japanese Ministry of Health, Labour and Welfare (2016) 2016 Welfare Labor White Paper. (In Japanese) http://www.mhlw.go.jp/wp/hakusyo/kousei/16/dl/all.pdf

[2] Japanese Ministry of Health, Labour and Welfare (2012) Reference Material on Health Japan 21 (The Second Term). (In Japanese) http://www.mhlw.go.jp/bunya/kenkou/dl/kenkounippon21_02.pdf

[3] King, A.C., Blair, S.N., Bild, D.E., Dishman, R.K., Dubbert, P.M., Marcus, B.H., et al. (1992) Determinants of Physical Activity and Interventions in Adults. Medicine and Science in Sports and Exercise, 24, S221-S236. https://doi.org/10.1249/00005768-199206001-00005

[4] Voorrips, L.E., Lemmink, K.A., van Heuvelen, M.J., Bult, P. and van Staveren, W.A. (1993) The Physical Condition of Elderly Women Differing in Habitual Physical Activity. Medicine and Science in Sports and Exercise, 25, 1152-1157. https://doi.org/10.1249/00005768-199310000-00011

[5] King, A.C., Rejeski, W.J. and Buchner, D.M. (1998) Physical Activity Interventions Targeting Older Adults A: A Critical Review and Recommendations. American Journal of Preventive Medicine, 15, 316-333. https://doi.org/10.1016/S0749-3797(98)00085-3

[6] Vestergaard, S., Kronborg, C. and Puggaard, L. (2008) Home-Based Video Exercise Intervention for Community-Dwelling Frail Older Women: A Randomized Controlled Trial. Aging Clinical and Experimental Research, 20, 479-486. https://doi.org/10.1007/BF03325155

[7] Teri, L., McCurry, S.M., Logsdon, R.G., Gibbons, L.E., Buchner, D.M. and Larson, E.B. (2011) A Randomized Controlled Clinical Trial of the Seattle Protocol for Activity in Older Adults. Journal of the American Geriatrics Society, 59, 1188-1196. https://doi.org/10.1111/j.1532-5415.2011.03454.x

[8] Chogahara, M., Cousins, S.B., Wankel, L.M. (1998) Social Influences on Physical Activity in Older Adults: A Review. Journal of Aging and Physical Activity, 6, 1-17. https://doi.org/10.1123/japa.6.1.1 
[9] Chogahara, M. (1999) A Multidimensional Scale for Assessing Positive and Negative Social Influences on Physical Activity in Older Adults. The Journals of Gerontology. Series B, Psychological Sciences and Social Sciences, 54, S356-S367. https://doi.org/10.1093/geronb/54B.6.S356

[10] McAuley, E. and Rudolph, D. (1995) Physical Activity, Aging, and Psychological Well-Being. Journal of Aging and Physical Activity, 3, 67-96. https://doi.org/10.1123/japa.3.1.67

[11] Larson, R. (1978) Thirty Years of Research on the Subjective Well-Being of Older Americans. Journal of Gerontology, 33, 109-125. https://doi.org/10.1093/geronj/33.1.109

[12] McAuley, E., Blissmer, B., Marquez, D.X., Jerome, G.J., Kramer, A.F. and Katula, J. (2000) Social Relations, Physical Activity, and Well-Being in Older Adults. Preventive Medicine, 31, 608-617. https://doi.org/10.1006/pmed.2000.0740

[13] Diener, E., Suh, E.M., Lucas, R.E. and Smith, H.L. (1999) Subjective Well-Being: Three Decades of Progress. Psychological Bulletin, 125, 276-302. https://doi.org/10.1037/0033-2909.125.2.276

[14] Taylor, L.M., Kerse, N., Frakking, T. and Maddison, R. (2018) Active Video Games for Improving Physical Performance Measures in Older People: A Meta-Analysis. Journal of Geriatric Physical Therapy, 41, 108-123. https://doi.org/10.1519/JPT.0000000000000078

[15] Larsen, L.H., Schou, L., Lund, H.H. and Langberg, H. (2013) The Physical Effect of Exergames in Healthy Elderly-A Systematic Review. Games for Health Journal, 2, 205-212. https://doi.org/10.1089/g4h.2013.0036

[16] Lund, H.H. and Jessen, J.D. (2014) Effects of Short-Term Training of Community-Dwelling Elderly with Modular Interactive Tiles. Games for Health Journal, 3, 277-283. https://doi.org/10.1089/g4h.2014.0028

[17] Matsuguma, H., Fujioka, S., Nakajima, A., Kaneko, K., Kajiwara, J., Hayashida, K., et al. (2012) Research and Development of Serious Games to Support Stand-Up Rehabilitation Exercises. Information Processing Society of Japan Journal, 53, 1041-1049. (In Japanese)

[18] Matsuguma, H., Fujioka, S., Nakamura, N., Harada, H., Hyakutake, E., Uchinoura, M., et al. (2012) Introduction of the Serious Game into Long-Term Care Health Facility to Support Stand Up-Sit down Exercise for Rehabilitation. Institute of Electronics, Information, and Communication Engineers Technical Report. Multimedia and Virtual Environment, 112, 13-17. (In Japanese)

[19] Kawabata, N., Miyaguchi, H., Kunishige, M., Ishizuki, C., Ito, Y., Harada, T., et al. (2017) Influence of Interaction among the Elderly through Amusement on Their Physiological Function: One-Month Introduction at a Day Care Service Center for the Elderly. Asian Journal of Occupational Therapy, 13, 23-30.

[20] Tonan, K., Sonoda, A. and Ono, Y. (1995) Production of the Subjective Well-Being Inventory Japanese Edition: It's Reliability and Validity. The Japanese Journal of Health Psychology, 8, 12-19. (In Japanese) https://doi.org/10.11560/jahp.8.2_12

[21] Ono, Y. and Yoshimura, K. (2010) WHO SUBI Manual. Second Edition, KANEKOSHOBO, Tokyo.

[22] Sell, H. and Nagpal, R. (1992) Assessment of Subjective Well-Being: The Subjective Well-Being Inventory (SUBI). Patient Education and Counseling, 28, 106-107.

[23] Karibe, H., Aoyagi, K., Koda, A. and Kawakami, T. (2011) Characteristics of the Salivary Alpha-Amylase Level in Resting Sublingual Saliva as an Index of Psychologi- 
cal Stress. Stress Health, 27, 282-288. https://doi.org/10.1002/smi.1358

[24] Nakamura, K. (2008) A "Super-Aged" Society and the "Locomotive Syndrome". Journal of Orthopaedic Science, 13, 1-2. https://doi.org/10.1007/s00776-007-1202-6

[25] Japan Locomo Challenge Promotion Conference. Locomotive Syndrome Pamphlet 2015. http://locomo-joa.jp/en/index.pdf

[26] Seichi, A., Hoshino, Y., Doi, T., Akai, M., Tobimatsu, Y. and Iwaya, T. (2012) Development of a Screening Tool for Risk of Locomotive Syndrome in the Elderly: The 25-Question Geriatric Locomotive Function Scale. Journal of Orthopaedic Science, 17, 163-172. https://doi.org/10.1007/s00776-011-0193-5

[27] Kanda, Y. (2013) Investigation of the Freely Available Easy-to-Use Software "EZR" for Medical Statistics. Bone Marrow Transplantation, 48, 452-458. https://doi.org/10.1038/bmt.2012.244

[28] Health and Welfare Statistics Association (2017-2018) Journal of Health and Welfare Statistics, 64, 456. (In Japanese)

[29] Mahoney, F.I. and Barthel, D.W. (1965) Functional Evaluation; The Barthel Index. Maryland State Medical Journal, 14, 61-65.

[30] Folstein, M.F., Folstein, S.E. and McHugh, P.R. (1975) “Mini-Mental State”. A Practical Method for Grading the Cognitive State of Patients for the Clinician. Journal of Psychiatric Research, 12, 189-198. https://doi.org/10.1016/0022-3956(75)90026-6

[31] Perneczky, R., Wagenpfeil, S., Komossa, K., Grimmer, T., Diehl, J. and Kurz, A. (2006) Mapping Scores onto Stages: Mini-Mental State Examination and clinical Dementia Rating. The American Journal of Geriatr Psychiatry, 14, 139-144. https://doi.org/10.1097/01.JGP.0000192478.82189.a8

[32] Furukawa, T.A., Kawakami, N., Saitoh, M., Ono, Y., Nakane, Y., Nakamura. Y., et al. (2008) The Performance of the Japanese Version of the K6 and K10 in the World Mental Health Survey Japan. International Journal of Methods in Psychiatric Research, 17, 152-158. https://doi.org/10.1002/mpr.257

[33] Hickey, T., Wolf, F.M., Robins, L.S., Wagner, M.B. and Harik, W. (1995) Physical Activity Training for Functional Mobility in Older Persons. Journal of Applied Gerontology, 14, 357-371. https://doi.org/10.1177/073346489501400401

[34] Tsutsumi, T., Don, B.M., Zaichkowsky, L.D. and Delizonna, L.L. (1997) Physical Fitness and Psychological Benefits of Strength Training in Community Dwelling Older Adults. Applied Human Science: Journal of Physiological Anthropology, 16, 257-266. https://doi.org/10.2114/jpa.16.257

[35] Yasunaga, A., Yaguchi, K. and Tokunaga, M. (2002) The Effects of Exercise Habits on Subjective Well-Being in the Elderly. Japan Journal of Physical Education, Health and Sport Sciences, 47, 173-183. (In Japanese) https://doi.org/10.5432/jjpehss.KJ00003390687

[36] Mihalko, S.L. and McAuley, E. (1996) Strength Training Effects on Subjective Well-Being and Physical Function in the Elderly. Journal of Aging and Physical Activity, 4, 56-68. https://doi.org/10.1123/japa.4.1.56

[37] Yamaguchi, M., Kanemori, T., Kanemaru, M., Mizuno, Y. and Yoshida, H. (2001) Correlation of Stress and Salivary Amylase Activity. Japanese Journal of Medical Electronics and Biological Engineering, 39, 234-239. (In Japanese)

[38] Takai, N., Yamaguchi, M., Aragaki, T., Eto, K., Uchihashi, K. and Nishikawa, Y. (2004) Effect of Psychological Stress on the Salivary Cortisol and Amylase Levels in Healthy Young Adults. Archives of Oral Biology, 49, 963-968. https://doi.org/10.1016/j.archoralbio.2004.06.007 
[39] Shimizu, R., Kondo, Y., Moriyama, Y., Tsukamoto, S., Hayashi, H., Hoshino, J., et al. (2012) Effect of Laughter Stimuli on Autonomic Nervous System and Its Sustained Effect. Journal of Japan Society of Nursing and Health Care, 14, 1-12. (In Japanese)

[40] Kitada, T., Ozaki, H., Nagata, T., Ishibashi, M., Machida, S. and Naito, H. (2016) Relationship between Physical Activity and Locomotive Syndrome after a 3-Month Exercise Intervention of Walking and Stair Climbing in Elderly Japanese Individuals. Juntendo Medical Journal, 62, 218-224. https://doi.org/10.14789/jmj.62.s218

[41] Studenski, S., Perera, S., Patel, K., Rosano, C., Faulkner, K., Inzitari, M., et al. (2011) Gait Speed and Survival in Older Adults. JAMA, 305, 50-58.

https://doi.org/10.1001/jama.2010.1923

[42] Kaplan, G.A. and Camacho, T. (1983) Perceived Health and Mortality: A Nine-Year Follow-Up of the Human Population Laboratory Cohort. American Journal of Epidemiology, 117, 292-304. https://doi.org/10.1093/oxfordjournals.aje.a113541 